\title{
An AR-based Gamified English Course in Vocational College through Interest-driven Approach
}

\author{
Dan Wang, Mas Nida Md. Khambari* \\ Faculty of Educational Studies, Universiti Putra Malaysia, Seri Kembangan, 43400, Selangor, Malaysia
}

Received October 27, 2019; Revised December 2, 2019; Accepted December 24, 2019

Copyright $\subseteq 2020$ by authors, all rights reserved. Authors agree that this article remains permanently open access under the terms of the Creative Commons Attribution License 4.0 International License

\begin{abstract}
In recent years, augmented reality (AR) technology's application has been explored in numerous disciplines. Many studies claimed that AR technology had significant advantages in enhancing learning interesting and boosting the understanding and collaborative learning etc. However, in China, most college students lack learning interest and adopt a passive method to learn English. In order to improve the learning situation, the researcher utilized the interest-driven creator (IDC) theory as the basis to design an AR-based gamified English course in vocational college. The study aimed to answer the following questions: (1) How does the AR-based gamified learning environment impact students' learning motivation in English course? (2) How does the AR-based gamified learning environment impact students' collaborative learning in English course? This study was conducted in a vocational college of China and the in-depth interviews were adopted to collect data. The results of the investigation revealed that students' learning motivation was enhanced through the change of teacher' role and using AR technology's virtual content. Additionally, the AR-based gamified learning environment can effectively enhance collaborative learning through strengthening the willingness of discussion and providing more opportunities, and the relaxed learning atmosphere.
\end{abstract}

Keywords English Course, Motivation, Collaborative Learning, AR Technology, Interest-driven Creator Theory

\section{Introduction}

The rapid development of information and communication technology significantly impacts educational field and changes the traditional teaching form. With the coming of the fourth industrial revolution which is driven by "artificial intelligence (AI) + 12tech" that consists of six digital transform and six analog transform technologies together with AI [1], the emerging technologies is bringing new innovations for education. Given the fact that technology revolution, in 2018, China's Ministry of Education issued the education informationization 2.0 action plan, which marks China will further develop and apply artificial intelligence and related technologies into educational field. Emerging technologies is gradually applied in different disciplines and the teaching form and environment are undergoing great changes in China. AR technology as one of the emerging technologies is also applied in different disciplines including English teaching and bring new teaching reform.

\section{Literature review}

AR technology allows virtual objects to superimpose on real objects in the same space and interact in real time [2]. When virtual objects are superimposed on the real images, it provides users with access to rich and meaningful multimedia content [3]. Because of the unique features of AR technology, numerous researchers explore the application in English teaching and claim that AR technology has significant advantages in English teaching [4]. The application of AR technology in English teaching often involved vocabularies learning [5, 6, 7]. In He, Ren, Zhu, Cai and Chen's [8] study, AR technology was utilized to present learning materials including virtual pictures, the meaning and pronunciation of words in English word learning. The vivid picture was superimposed on English word card, which improved children's interest in learning.

Another study conducted by Chen, Zhou, Wang and $\mathrm{Yu}$ [9] also used AR cards through scanning the maker to see 3D scenes and 3D models of the word and hear the pronunciation. The difference was that children can interact with the 3D model by clicking on the screen. The result revealed that AR technology can inspire learning interest and improve participation. The similar feature of display and interaction of AR technology was also utilized by Hsieh, Kuo and Lin [10]. In this study, course content 
was based on English prepositions of place with multimedia formats including text, voice, graphic, movie and interaction. The results pointed out the AR-based English learning was novel and interesting for students learning. According to the literature review, it is obvious that AR technology has significant advantages in enhancing learning interest and interaction in English learning.

However, there is a common characteristic in educational practice among the Asian countries, namely examination-driven [11]. In college English learning, this feature is also obvious. Learning English is usually to get a better score and acquire a certificate by adopting the mechanical learning way which means unhappy and passive learning. This is a typical phenomenon that students are extrinsically motivated to learn and lack of interest. Because the examination-driven trend, traditional English classroom always adopts the teacher-centred approach to import the knowledge, which results students lost interest and cannot engage in active learning [12]. Therefore, how to improve the English sentence learning's initiative need to pay more attention on the change of instructor's teaching approach and students' interest and engagement. Ottenbreit-leftwich and Ertmer [13] pointed out effective technology was a strong assistant for teachers to change the traditional teacher-centre class and to create an active learning environment. The emerging AR technology provides the new approach to improve the problem of English learning.

Therefore, in this study, researchers have utilized the interest-driven creator (IDC) theory as the basis to design an AR-based gamified English course in vocational college. IDC theory was proposed by Tak-Wai Chan's team [11] and their studies pointed out when students were motivated to learn with their own interest, they would eventually develop their own ways of learning habit and create new knowledge after immersing into a repeated technology-supported learning environment. IDC theory provides three anchored concepts namely interest, creation and habit, and each of them undergoes a coherent learning process that form a loop. This theory claims that interest is regarded as the crucial component and should be run through the whole learning process. Creation make students feel the sense of satisfaction and achievement. Habit is a sign that students change to an interest-driven creator namely an autonomous learning learner. In this study, researchers primarily used the interest loop. The technology-supported environment was provided by AR technology. According to the IDC theory, interest is regarded as the crucial component and context drives the interest of learners in an activity. It includes triggering, immersing and extending. Therefore, this study combined the feature of AR technology which was verified that it could significantly enhance learning interest and easily incorporate the way of gamification to design a learning model to explore the English sentence leaning.

\section{Research Methodology}

This study was conducted in the course of College English and fifty vocational students participated this activity. The in-depth interviews were conducted to collect data. The researcher selected the interviewees from each group randomly until the data reached the saturation. The data collected by interviews was analyzed with the assistance of Nvivo software and with the guidance of the research questions, the themes were refined through coding and categorizing the interview transcripts.

\section{Design of the Model}

The model was implemented in the course of College English. In order to master the English sentence expression regarding the campus building. The model was designed as follows.

\subsection{The rationale for design}

According to IDC theory, the whole leaning process was designed to an active leaning process through the AR-based gamified leaning approach. In the learning process, the AR technology was applied the three main points.

\subsection{Design of an AR-based gamified English course}

Collins [14] stated that it was significant to construct the efficient learning environment to learning English in the area of technology-assisted language studying. In the whole learning process of this model, AR technology was used for three points to construct the learning environment by overlaying the virtual graphics onto real-world objects.

Point 1 was lead-in and to learn the sentence expression. The five pictures of language lab, library, dining hall, teaching building and cinema were used as markers through Easy AR platform which was a free service platform for AR technology.

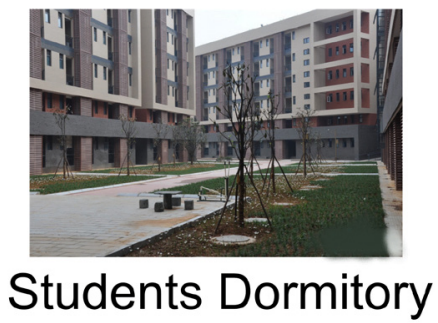

Figure 1. One of the markers for lead-in

After the processing of Easy AR platform, students could use mobile phone to scan the pictures by importing the program. Subsequently, the video of English introduction about one of the buildings, the 3D graphics and a conversation video regarding how to find buildings 
would be overlaid onto real picture so as to construct the learning environment.

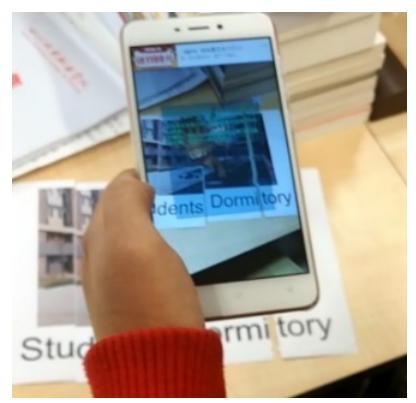

Figure 2. The introduction of students' dormitory

Point 2 was the game level which was used to examine the learning effect. Under the guidance of IDC theory, in this course, the traditional teacher role was changed and teacher played the game level. The game level required the students to scan the teacher's item which could be captured easily by mobile camera. The video regarding the requirement of the game levels would be overlaid onto the image. Students needed to describe the building's location.

Meanwhile, the virtual 3D cartoon character was designed throughout the game process. When the player scanned images, a virtual 3D cartoon character representing the player would appear.

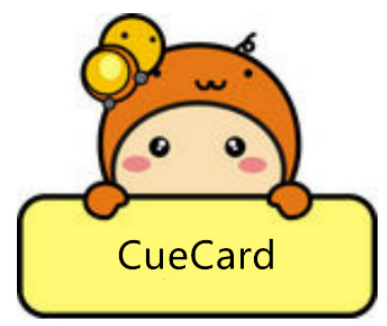

Figure 3. The item for the teacher

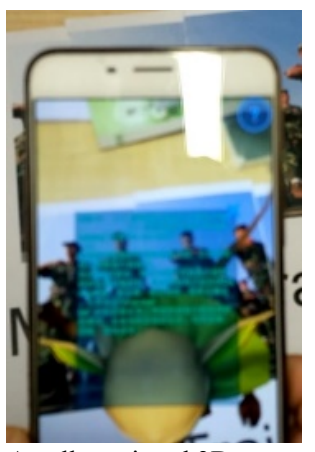

Figure 4. A yellow virtual $3 \mathrm{D}$ cartoon character

Point 3 was game over. When students stitched the correct campus map and scanned the picture of game over, the video about the introduction of the whole campus and congratulations were shown on the real map. It proved that the team had finished the game successfully and reached the teaching goal.

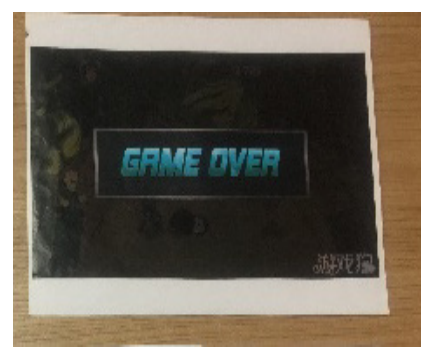

Figure 5. The markers for game over

\subsection{Game rules}

The game had five parts and each part included one learning content of building. Besides, each team with ten students worked together to finish each part. Therefore, there were five small teams and each of which chose a picture randomly and then scanned the picture by mobile phone to begin the game.

After that, players entered the point 1. Each small team members needed to interact with the content alone and discussions were allowed between team members after independent thinking. Then players needed to describe the building's basic situation and how to find it. After getting the answers, the players went to the game level which was played by teacher. The game level had the right to ask the small teams went back to point 1 and also gave them the suggestions. After the five small teams finished the work respectively, they entered the point 3 together, then the game was over.

\section{Findings and Discussion}

According to data analysis, there were two themes which emerged from the interview transcript to answer the first question, namely the use of technology and the change of teacher's role.

1. How does the AR-based gamified learning environment impact students' learning motivation in English course?

(1) The use of technology

The first theme emerged from the results was the use of technology. When students studied English sentence in the AR-based gamified learning environment, the characteristic of AR technology was found that it could positively impact students' learning motivation. Two participants stated that the use of the vivid AR content inspired their enthusiasm to learn English sentence.

I'm very excited and the virtual graphics are very interesting. Besides, the virtual interpretation of knowledge can overlay onto the real pictures, which make me feel curious about the learning of English sentence.

(Dai yuanyuan)

I like the $3 D$ character and it is interesting, which makes me want to know what we learn in the English 
course. Furthermore, the explanation of knowledge provided by AR technology is also interesting.

(He zhiyuan).

Additionally, the findings also revealed that apart from the interesting AR learning content enhance students' learning motivation. The operation of using $\mathrm{AR}$ technology also attracted students to learn.

I think the virtual graphic, video and $3 D$ character are all interesting and I also like to play with my phone, which makes me want to try to use my phone to scan something. The use of AR technology attracts me to begin to learn English.

\section{(Tang jianming)}

I like use my phone to scan the picture, because there always something new comes out and the learning contents are also very interesting.

(Zhang mingyang)

Furthermore, the finding also showed that the use of AR technology effectively maintain learning interest and immersed students in learning environment.

I like to use my phone to scan the pictures and the content is interesting and different every time, which attracts me to continue to find and learn, especially, when I scan one picture, one vivid virtual character superimposed on the image. I feel very excited and want to learn more about the English content. I am totally immersed in the study.

(Zhu ya)

Hsieh and Lin [15] claimed that the virtual contents were overlaid on the real objects, students could obtain the sense of excitement. The findings above showed that AR environment can attract students' interests in English learning [16]. Specifically, it could significantly trigger the students' interest in English learning through using 3D character and virtual graphics and video. Furthermore, as the IDC theory claimed that interest is regarded as the crucial component and learning context drives the interest of learners in an activity. In this study, the operation of AR technology not only inspires students' learning enthusiasm but also effectively remain vocational students' learning interest.

\section{(2) The change of the teacher's role}

Some participants also pointed out that the change of the teacher's role in this learning environment effectively enhanced their learning motivation. Compared with traditional English course, the new setting of the teacher' role in class attracted students to learn English.

The teacher's role is very fresh, novel and interesting. In other courses, most teachers just read the PowerPoint whose teaching approach are always like that. In this course, teacher can engaged in the learning process with us, which enhanced my learning interest and want to learn something in the class.

(Wu dan)
Apart from that, the change of the teacher's role provided more learning interaction, which attracted and maintained students' learning motivation. Two interviewees expressed that in the interaction, they began to think their knowledge weakness and tried to find the solution.

The teacher becomes a virtual character, which is very interesting. Furthermore, the teacher as a virtual character can give us the feedback for the content of previous studying in point 1 , and the interaction enhances the learning interesting. Although our group did not past the game level directly, our group was also very excited and came back to learn again and discussed where we should learn again.

(Xu qian)

It is different from the traditional course I experienced, the teacher participates in the game, which is very interesting. Besides, in this course, the teacher can interact with us and provide some feedback and suggestion. Our group feel excited and learn seriously. We are all immersed in finding how to use the English sentence to past the game level.

\section{(Zhang ke)}

According to the aforementioned results, it indicated that the innovative change of teacher's role in this environment improved the students' interests in English learning. Besides, in the learning process, the finding showed that students liked the new role of teacher and thought the change of teacher's role maintained their learning interest. Furthermore, according to IDC theory, extending interest was one of the most important component of interest formation. Extending interest implied that students try to look for solutions, which is the compliance with the extending component of interest loop [17]. In this study, it was revealed that students try to think how to use the English sentence properly, whose ideas or thinking may equip them when they encounter the similar situation in the real life.

2. How does the AR-based gamified learning environment impact students' collaborative learning in English course?

(1) The use of AR-based gamified strategy

The findings revealed that the use of AR-based gamified strategy enhanced the intention of discussion. Students expressed that they were more willing to participate the discussion.

Because it is very clear and interesting that the learning content is introduced through virtual content, the discussions afterwards with team members become positive. Meanwhile, The well-designed point land 2 which supported by the virtual images, video and $3 D$ character also guided our discussion and inspired our group members' discussion enthusiasm.

(Li juncheng)

The learning materials are very interesting and our 
group members are all excited. In order to finish the game successfully, our team need to complete our own parts in part 1 and 2. Therefore, discussion is treated seriously.

\section{(Zhang xing)}

In addition to enhance the willingness of discussion, some students also pointed out that the AR-based gamified strategy used in the study also provide more space and opportunities to think and discuss, which boost their collaborative learning.

When we begin to scan images to learn, our group have chance to discuss the learning materials and we can look at ourselves phone and express our ideas. Besides, the interaction with teacher also provides more opportunities for us to think and discuss.

\section{(Xia yong)}

Khambari [17] pointed out that in an interest-driven activity, the use of technology can provide students more opportunities of interaction and content engagement. In this study, the results of investigation also showed the AR learning environment provided the more opportunities for students to attend the collaborative learning. Especially, with regards to AR technology, it was found that AR technology integrating the gamification form acquired better effect [18].

In this course, the gamified form especially the role of teacher provides many suggestions for our group, which is interesting and also makes us to discuss more detailedly in later repeated learning.

\section{(Qin liang)}

The AR learning materials provide chance for our group to discuss new English sentences. Meanwhile, when we interact with teacher, the game level also provides some suggestions for us to learn and discuss. In this course, I feel we have many opportunities to discuss and I also like the way of discussion with teacher and my group members.

(Zhu yang)

(2) The relaxed learning atmosphere

Some interviewees expressed that the relaxed learning atmosphere both in the whole learning environment and among the group members boost their collaborative learning. Two participants commented that the relaxed atmosphere enhanced their willingness of discussion and reduced the pressure of participation.

I really hate the traditional teaching approach, the whole learning environment is boring and no attraction for me to discus. This learning process is relax and it is without the pressure of traditional teaching form, which makes me to want to try to participant in the group.

(Wang jiao)

Actually, my English is very poor and I don't want to discuss anything with classmates before. But in this class, we can scan the picture to acquire the interesting vivid learning content. The atmosphere between the group is relaxed and exited, which makes me want to engage in the group to discus and find some new learning content.

\section{(Ma hua)}

These excerpts showed that in an interest-driven activity, the use of technology and integrating proper learning strategy not only provided the more space and opportunities to think and discuss but also positively impact students' internal participative willingness. Meanwhile, the relaxed learning atmosphere was crucial for students to engage in learning actively and autonomously.

\section{Conclusion}

Based on the result of interviews, it was particularly evident that the model can effectively enhance students' learning motivation through the change of teacher' role and using AR technology's vivid virtual content. Sandholtz [19] also claimed that it was significant to refine the role of teacher in the technology environment. In this study, the new setting of the teacher' role and more learning interaction with teacher attracted and maintained students' learning motivation. Additionally, the findings of study also pointed out this model can significantly enhance collaborative learning. The use of technology-based gamified strategy enhanced the intention of discussion and provide more space and opportunities for collaborative learning. Furthermore, the relaxed learning atmosphere enhance their willingness of discussion and reduce the pressure of participation.

According to the finding, it implied that when researchers applied an interest-driven approach to design a course, a proper technology is essential for constructing an active learning environment to enhance students' motivation and collaborative learning. Besides, the new role of teacher also need to combine the specific form to design carefully in the interest-driven learning environment, which may impact students to extend interest in the further.

\section{REFERENCES}

[1] Lee, M., Yun, J., Pyka, A., Won, D., Kodama, F., Schiuma, G., \& Yan, M. R., How to respond to the Fourth Industrial Revolution, or the Second Information Technology Revolution? Dynamic new combinations between technology, market, and society through open innovation, Journal of Open Innovation: Technology, Market, and Complexity, Vol.4, No.3, 21, 2018.

[2] Azuma, R. T., A survey of augmented reality, Presence: Teleoperators \& Virtual Environments, Vol.6, No.4, 355-385, 1997.

[3] Billinghurst, M., Kato, H., \& Poupyrev, I., The magicbook-moving seamlessly between reality and virtuality, IEEE Computer Graphics and applications, Vol.21, No.3, 6-8, 2001. 
[4] Li, S., Chen, Y., \& Vorvoreanu, M., A pilot study exploring augmented reality to increase motivation of Chinese college students learning English, The ASEE Computers in Education (CoED) Journal, Vol. 6, No.1, 23, 2015.

[5] Koutromanos, G., Sofos, A., \& Avraamidou, L., The use of augmented reality games in education: a review of the literature, Educational Media International, Vol.52, No.4, 253-271, 2015.

[6] Chen, C. P., \& Wang, C. H., The effects of learning style on mobile augmented-reality-facilitated English vocabulary learning, Information Science and Security (ICISS), 1-4, 2015.

[7] Hsieh, M. C., \& Lee, J. S., AR marker capacity increasing for kindergarten English learning, International Multi Conference of Engineers and Computer Scientists 1, 663-666, 2008.

[8] He, J., Ren, J., Zhu, G., Cai, S., \& Chen, G., Mobile-based AR application helps to promote EFL children's vocabulary study, 2014 IEEE 14th International Conference on Advanced Learning Technologies, 431-433, 2014.

[9] Chen, Y., Zhou, D., Wang, Y., \& Yu, J., Application of Augmented Reality for Early Childhood English Teaching, International Symposium on Educational Technology (ISET), 111-115, 2017.

[10] Hsieh, M. C., Kuo, F. R., \& Lin, H. C. K., The effect of employing AR interactive approach on students' English preposition learning performance, Journal of Computers and Applied Science Education, Vol.11, 45-60, 2014.

[11] Chan, T. W., Looi, C. K., Chen, W., Wong, L. H., Chang, B., Liao, C. C., \& Jeong, H., Interest-driven creator theory: towards a theory of learning design for Asia in the twenty-first century, Journal of Computers in Education, Vol. 5, No.4, 435-461, 2018.

[12] Pan, C., \& Wu, H., The Cooperative Learning effects on English reading comprehension and learning motivation of EFL freshmen, English Language Teaching, Vol.6, No.5, 13-27, 2013.

[13] Ottenbreit-leftwich, E., \& Ertmer, P., Teacher technology change. How knowledge, beliefs and culture intersect, Journal of Research on Technology in Education, 2010.

[14] Collins T.G., English class on the air: mobile language learning with cell phones, the Fifth IEEE International Conference on Advanced Learning Technolo-gies, 5-8, 2005.

[15] Hsieh, M. C., \& Lin, H. C. K., Interaction design based on augmented reality technologies for English vocabulary learning, the 18th International Conference on Computers in Education 1, 663-666, 2006.

[16] Liu, T. Y., Tan, T. H., \& Chu, Y. L., QR code and augmented reality-supported mobile English learning system, Workshop of Mobile Multmedia Processing, 37$52,2008$.

[17] Khambari, M. N. M. (2019). Instilling innovativeness, building character, and enforcing camaraderie through interest-driven challenge-based learning approach. Research and Practice in Technology Enhanced Learning,
14(1), 19.

[18] Xu, H., Song, D., Yu, T., \& Tavares, A. (2017). An Enjoyable Learning Experience in Personalising Learning Based on Knowledge Management: A Case Study. Eurasia J. Math. Sci. Technol. Educ, 13, 3001-3018.

[19] Sandholtz, J. H., Teaching with technology: Creating student-centered classrooms, Teachers College Press, New York, 1997. 